\title{
The General Attitudes of Egyptian University Faculty, Students and Staff towards Genetically Modified Foods
}

\author{
S. A. S. Ismail \\ Department of Food Hygiene, Faculty of Veterinary Medicine Suez Canal University, Ismailia, Egypt \\ Correspondence should be addressed to: S. A. S. Ismail; soadismail@yahoo.com
}

Received 10 April 2013; Accepted 21 May 2013; Published 28 August 2013

Academic Editor: Kamelia M. Osman

Copyright (C) 2013 S. A. S. Ismail. Distributed under Creative Commons CC-BY 3.0

\begin{abstract}
Biotechnology offers a variety of potential benefits and risks. On one hand, it has helped enhance food production and improve the quality and nutritional value of food. On the other hand, concerns have been raised about the health, environmental, and economic repercussions of the use of biotechnology. Consequently, consumer response toward genetically modified food (GMF) has shown a large degree of variance from one country to another, and even within the same country. The present study investigates university employees and students' attitudes toward GMF in the Egyptian context. A questionnaire was used to test the knowledge and opinions about GMF of Egyptian university faculty, staff, and students $(n=300)$. Results of the study reveal that the majority of the respondents prefer to buy healthier, more nutritious, and safer foods that contain less pesticides. Surprisingly, only $4 \%$ of those same respondents reported that they were aware of the presence of GMF in the Egyptian market; the majority of the respondents showed total unawareness of agricultural biotechnology and its prevalence in their lives. Results also showed that food safety, health, nutritional value, and taste were the major issues affecting the purchase and consumption of GMF while price and religious restrictions played a minor role. When it comes to the type of GMF, the respondents were more forgiving of plant-based GMF than they were of animal-based GMF; while 50\% of the respondents approved plant-based GMF, only $16.7 \%$ approved animal-based GMF.
\end{abstract}

Keywords: Genetically modified food, GM food, attitudes, Egypt.

\section{Introduction}

Biotechnological applications are increasingly playing a bigger role in medical, agricultural, and industrial fields alike. One byproduct of such biological applications in the field of agriculture is genetically modified (GM) food. GM food is derived from genetically modified organisms (GMOs) which have had specific changes introduced into their DNA by genetic engineering techniques. Selected individual genes with specific traits are transferred from one organism to another. Such genetic modification causes the GMOs to gain new characteristics they would not have gained if they were allowed to grow naturally (Verma et al., 2011).

Countries that grew the most transgenic crops in 2010 were the United States, 45\%; Brazil, 17\%; Argentina, 15\%; India, 6\%;

Cite this Article as: S. A. S. Ismail (2013), "The General Attitudes of Egyptian University Faculty, Students and Staff towards Genetically Modified Foods," International Journal of Veterinary Medicine: Research \& Reports, Vol. 2013 (2013), Article ID 890307, DOI: 10.5171/2013.890307 
Canada, 6\%; China, 2\%; Paraguay, 2\%; Pakistan, 2\%; South Africa, 1\%; and Uruguay 1\% (El-Nawawy, 2012). Over the past few years, GM crops have witnessed a rapid and continuing increase all over the world. Consequently, genetically modified organisms have become a part of our environment and food chain due to the large increase in crop area planted with GM crops (Pattron, 2006).

Companies producing and marketing GM food often proclaim that such food provides greater resistance to pests and viruses, higher nutritional value, and longer shelf life. However, environmental groups and consumer protection agencies have repeatedly voiced their concerns about the health, environmental, and economic repercussions of GM food (Pattron 2000). Examples of such repercussions included antibiotic resistance, cross breeding, herbicide-tolerant crops, pesticideresistant insects, biodiversity cross contamination, allergens and other health effects (Batalion 2000).

Laws to regulate the identification and labeling of GM foods vary in different countries; the United States and Canada do not require mandatory labeling of GM foods, however in certain regions such as the European Union, Japan, Malaysia and Australia, governments have required labeling of GM foods. Citing, the undesirable effects health and environmental effects of GM foods, some countries have instituted a total ban on importing food products that contain GM ingredients such as is the case in Egypt (Egyptian Legislation No. 242, 1997).

Even though the Egyptian parliament has enacted a 1997 law that bans the import of food products known to contain GM ingredients, tons of such products find their way on the tables of millions of Egyptians every day. This is mostly due to lack of government resources and lax law enforcement considering that Egypt is not self-sufficient in food production and as a consequence relies heavily on foreign imports of food to satisfy its needs (Egyptian Ministry of Trade and Industry, 2012); it is estimated that Egyptians spent
5.34 billion dollars on food imports in 2012 alone, (Egyptian Central Agency for Public Mobilization and Statistics, 2013). The majority of these food imports came from countries known to produce and export GM food such as the United States, Canada, Argentina, and China.

Since none of these banned food products are properly labelled as GM foods, it is very likely that consumers in Egypt are left out in the dark when it comes to the true nature of the ingredients and safety of these imported foods they consume on a daily basis. No studies have been conducted in Egypt that actually investigate consumer opinions about genetically modified foods as far as we can tell. Therefore, the present study aimed to investigate consumer awareness of GM foods and provide recommendations to control the use of genetically modified foods.

\section{Methodology}

Data for the present study were collected during the time period between January 2012 and December 2012. A questionnaire consisting of a total of 25 questions based on the work of Hallman et al., (2003) was used; slight modifications were made to wording of the questionnaire items to reflect the Egyptian habits. The questionnaire collected some basic demographic information about the respondents and focused on their awareness of GM food, labeling of GM foods, applications of genetic modification, and consumption patterns of GM food. The questionnaire was distributed to a stratified sample of faculty members, students, and workers at Suez Canal University, Ismailia, Egypt according to established scientific and ethical criteria (Pattron 2000). Copies of the questionnaire were distributed in person; three hundred targeted respondents completed the questionnaires and returned them to the Food Hygiene Department, Faculty of Veterinary Medicine, Suez Canal University, and Ismailia, Egypt. Statistical analysis was performed using standard statistical methods (Swinscow 1991). 


\section{Results and Discussion}

\section{Demographics:}

Out of the 300 respondents who competed and returned the questionnaire, $56 \%$ were males and $44 \%$ females. Their ages ranged from 18 years to 68 years. Ten percent of the respondents were university students; $31 \%$ senior faculty members; $13.3 \%$ junior faculty members; $16 \%$ technicians; $13.7 \%$ administrative staff; and $16 \%$ custodial staff. Sixteen point six percent of the respondents completed primary school; $16.6 \%$ secondary school; $23.3 \%$ held college degrees; and $43.5 \%$ held graduate degrees.

\section{Awareness of GM Foods:}

To measure consumer awareness of biotechnology and GM food, the questionnaire directed the respondents to state how much they know about biotechnology and genetic engineering or genetic modifications.

Fifty seven percent of the respondents had heard or read not much or nothing at all about genetic modification or biotechnology while $30 \%$ had heard or read some. Only $13.3 \%$ had heard or read a great deal about it (figure 1).

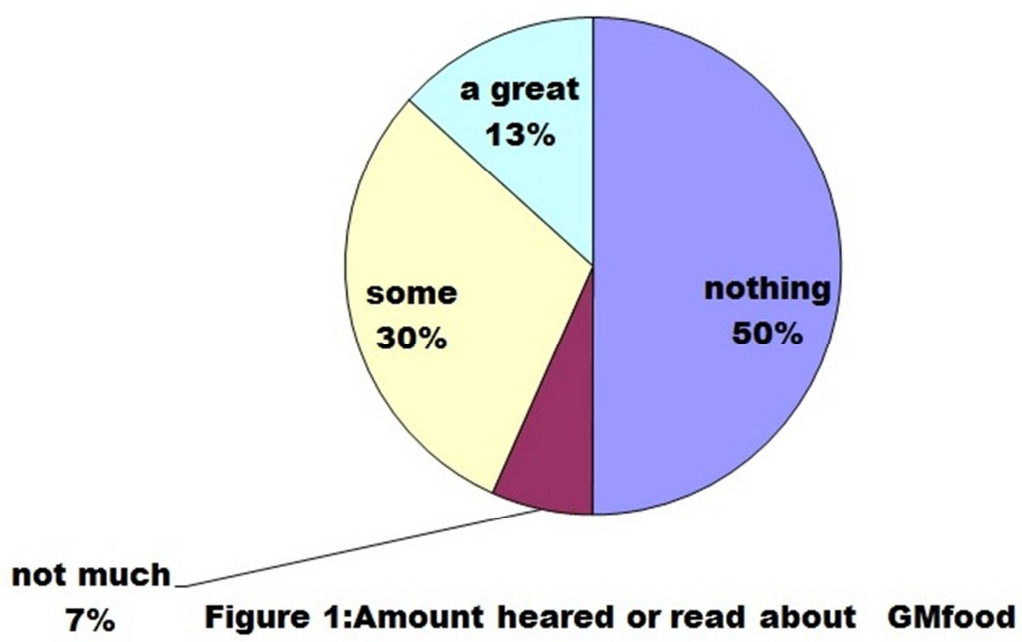

Almost two thirds of the respondents (63.3\% to be precise) did not discuss biotechnology or genetic engineering or modification with any one while only
38.6\% have discussed these items (figure 2). These findings indicate that Egyptians are not spending a lot of time talking about GM foods. 


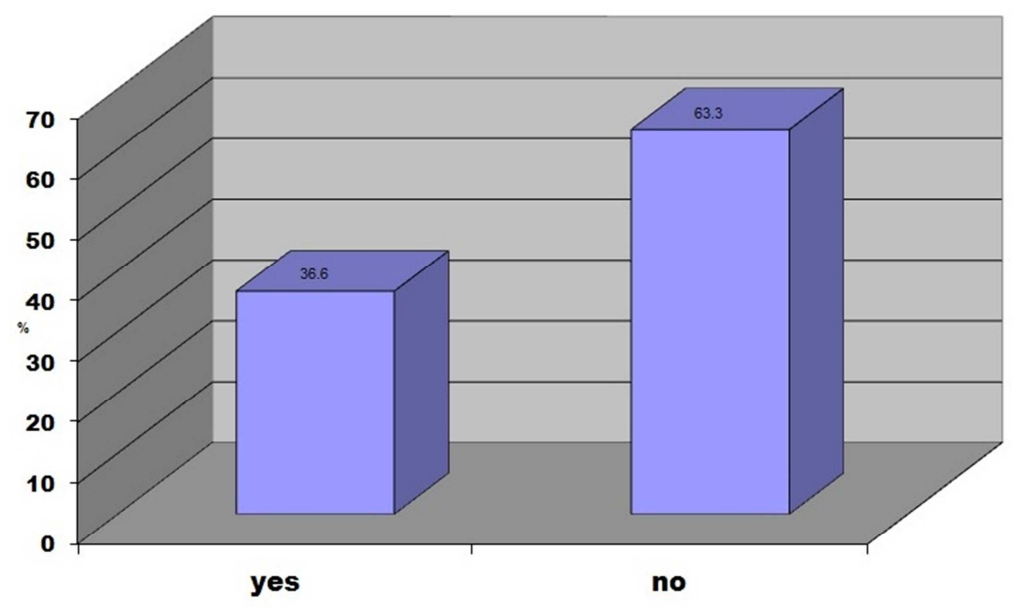

$\square$ Series1

Fig2: Frequency of discussion of biotechnology

Despite of the abundance of products with GM ingredients in the Egyptian market nowadays, only $16.6 \%$ of the respondents were aware that GM food products are currently sold in the grocery stores while
$13.3 \%$ of the respondents did not believe such products were available in the grocery stores. The majority of the respondents $(70 \%)$ were not sure (Figure 3$)$.

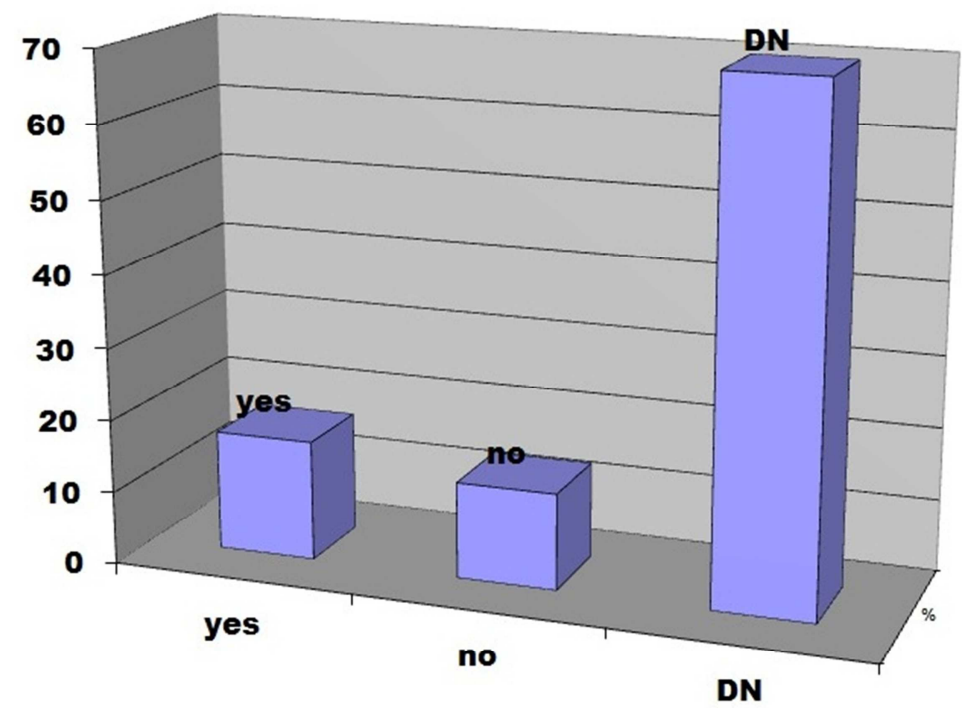

Figure3:Aewareness of GM food in supermarkets

As shown in Figure 4, only $4 \%$ of the respondents reported that they had consumed food containing GM ingredients.
Seven percent of the respondents said they had not, and $88 \%$ were not sure. 


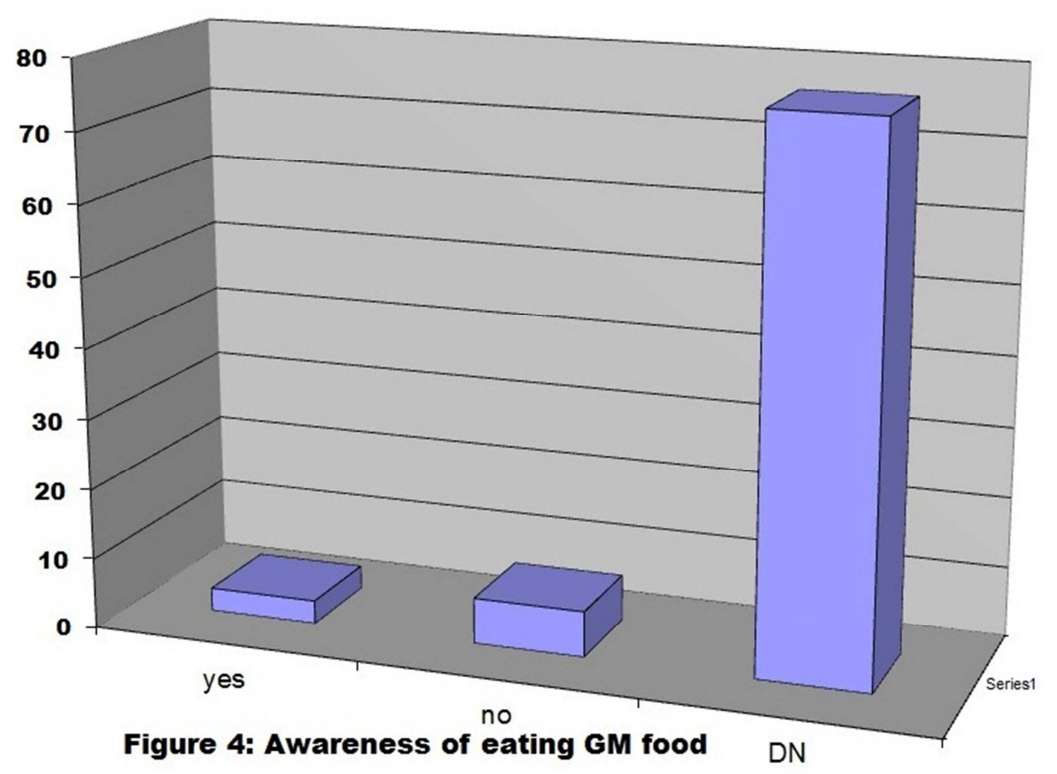

These findings illustrate that Egyptians are unaware of genetically modified food and its prevalence in their lives.

\section{Knowledge about Science and Technology:}

When asked to rate their knowledge about science and technology, $37 \%$ of the

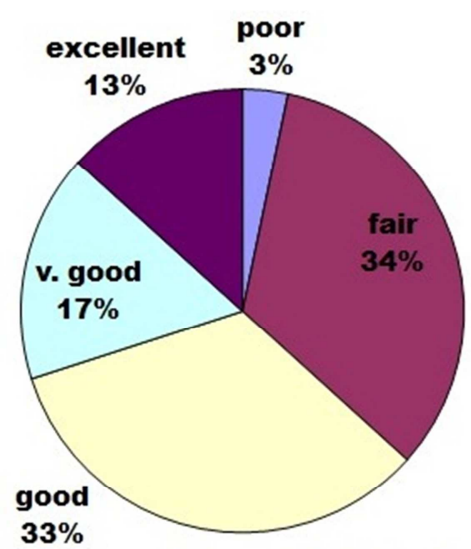

Figure 5:Self rated knowledge of science and technology respondents rated their knowledge as fair or poor while $33 \%$ rated it as good and $30 \%$ thought that their understanding was very good or excellent (Figure 5).
Similarly, most respondents reported that they do not know much about biotechnology, genetic engineering, or genetic modification. The majority of respondents claimed to know very little
(17\%) or nothing at all (53\%) about biotechnology. In contrast, $20 \%$ of the respondents said they know a fair amount while only $10 \%$ said they know a great deal about the subject (Figure 6). 


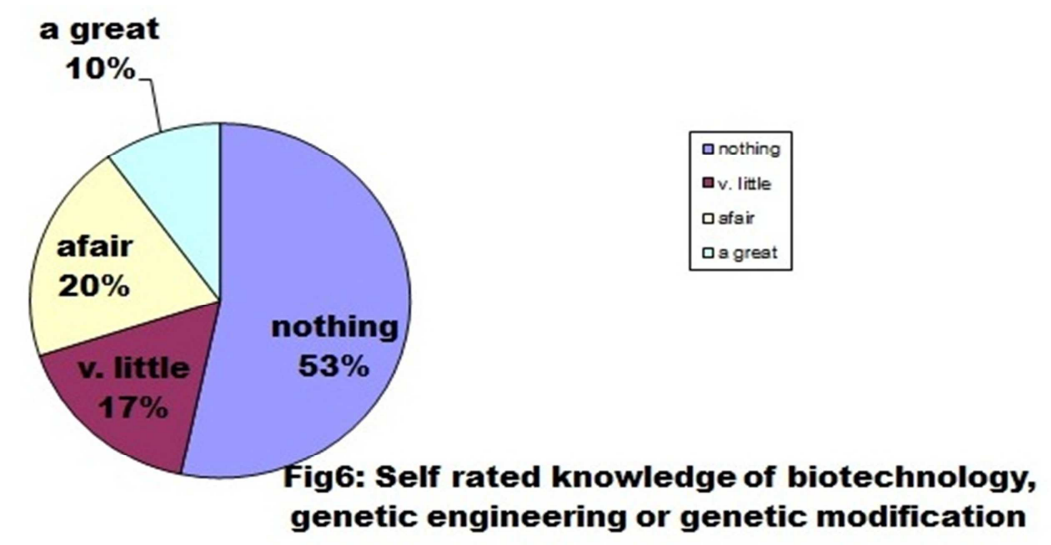

\section{How Do Egyptians Feel about GM Foods?}

Our survey indicates that Egyptians' opinion about GM foods are divided as shown in Table 1. Almost half of the respondents (49.9\%) approved plant based GM foods whereas only $36.7 \%$ approved animal based GM foods. It is obvious that Egyptians express greater support for the genetic modification of plants than they do for animals, fewer respondents reported approval of animal based products compared to plant based products, and the majority disapproved animal based products $(16.6 \%$ somewhat disapprove and $40 \%$ strongly disapprove). A possible reason is that people usually have a higher risk expectation of animal products than plant ones because of the spread of BSE in recent years.

Table 1: Approval of Genetically Modified Food Products.

\begin{tabular}{|l|l|l|}
\hline & Plant based \% & Animal based \% \\
\hline Strongly approve & 33.3 & 16.7 \\
\hline Somewhat approve & 16.6 & 20 \\
\hline Somewhat disapprove & 23.3 & 16.6 \\
\hline Strongly disapprove & 16.3 & 40 \\
\hline Refused & 10.5 & 6.7 \\
\hline
\end{tabular}

\section{Acceptability of GM Foods}

Food safety (46.6\%), health (46\%) nutritional value and taste $(33.3 \%)$ were the major issues affecting the purchase of GM foods as a safe source of food. Apart from these issues, price (13.3\%) and religious reasons $(16.6 \%)$ played a minor role in the purchase and consumption of GM foods. It is clear that price does not appear to influence consumers as much as other benefits when buying GM foods.

When the respondents were asked to agree or disagree with the statement "I would be unhappy if I were served GM food in a restaurant without knowing it," 26.6\% agreed, while $20 \%$ disagreed, and the rest (53.4\%) did not know. In response to another question with a similar but slightly different meaning "If food I was eating in a restaurant contained GM food, I would not mind", 16\% agreed; $33.3 \%$ disagreed; and $50.7 \%$ did not know. This disparity in responses suggests that Egyptians have not made up their minds about GM foods.

The results shown in Table 2 explain why Egyptians consider genetic modification unacceptable. Forty three percent believe that GM food are unhealthy for humans, animals, and the environment while $6.6 \%$ thought genetic modification of food changes its taste and nutritional value. Only $3.3 \%$ consider it just wrong while $16.6 \%$ believed it violates religious or ethical principles. 
Table 2: Why Do Egyptians Consider Genetic Modification Unacceptable?

\begin{tabular}{|l|l|}
\hline Cause & $\%$ \\
\hline Religious & 16.6 \\
\hline Unhealthy for human & 16.6 \\
\hline Unhealthy for animals & 10 \\
\hline Unhealthy for the environment & 6.6 \\
\hline Changes the taste or nutritional value & 6.6 \\
\hline Is just wrong & 3.3 \\
\hline Others & 3.3 \\
\hline
\end{tabular}

\section{Concerns Associated with GM Foods}

Egyptians report concerns about potential risks to human health associated with GM foods. Forty percent of the respondents believe it is unsafe to consume genetically modified food while $13.3 \%$ said it is safe. Respondents also seem concerned about the potential unintended consequences related to technology. More than one quarter of the respondents $(26.6 \%$ to be exact) feel serious accidents involving GM foods are bound to happen and 33.3\% feel that GM foods threaten the natural order of things; only $10 \%$ of the respondents agreed with the statement that "GM food presents no danger for future generations" while $40 \%$ disagreed.

These results indicate that while most Egyptians say they know little about genetic modification, many may be worried about the potential long-term consequences of GM foods.

The results in Table 3 show that $53.3 \%$ of the respondents thought genetic modification would improve their quality of life while $46.6 \%$ thought it would make their quality of life worse. These measures indicate that Egyptians are slightly more positive about genetic modification.

Table 3: How Egyptians Think GM Food Will Affect their Quality of Life

\begin{tabular}{|l|l|}
\hline & $\%$ \\
\hline much better & 43.3 \\
\hline somewhat better & 10 \\
\hline Somewhat worse & 20 \\
\hline Much worse & 26.6 \\
\hline
\end{tabular}

\section{Labeling of Genetically Modified Foods}

When the respondents were asked how often they read food labels, 33\% reported that they never read them; 3\% reported they rarely read them; $17 \%$ sometimes; $17 \%$ frequently; and $30 \%$ said they always read food labels (Figure 7). 


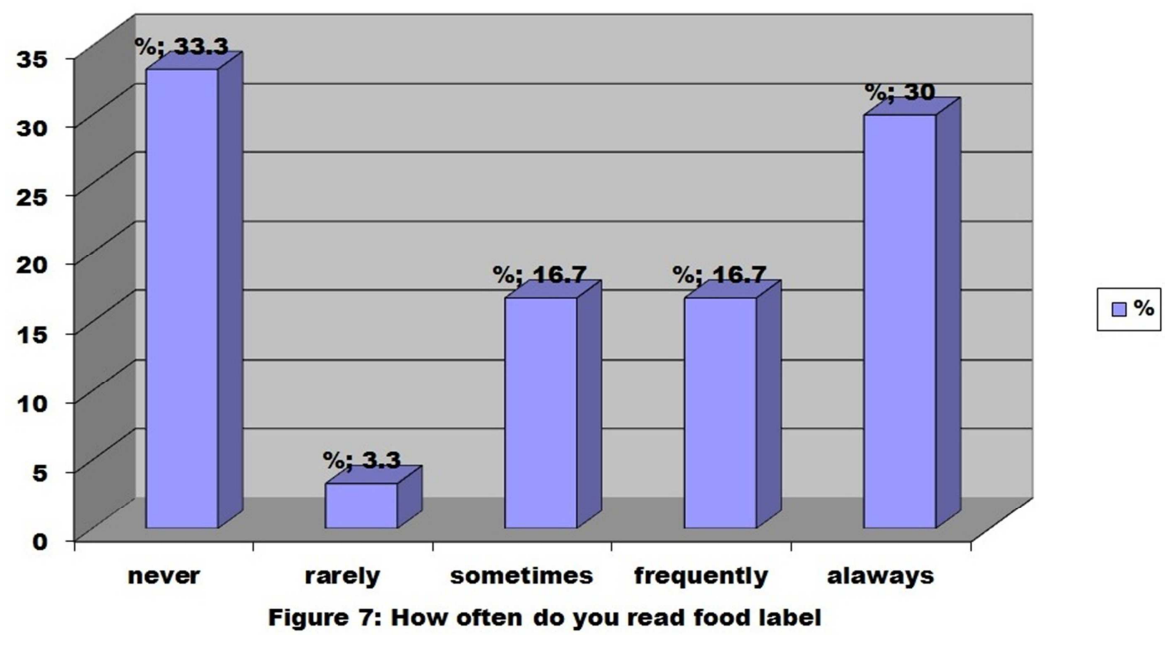

When asked about additional information on the food labels, $33.6 \%$ said that there was no additional information they were interested in seeing on food labels while $66.4 \%$ of the respondents wanted to see additional information.

When asked how labeling GM food would affect their purchasing decision, 33\% said it would make no difference and $33 \%$ said it would make them less willing to purchase the product while only $7 \%$ of the respondents said they would be more willing to buy GM food and $17 \%$ refused to answer.

More than half of the respondents (53.3\% to be precise) said that they would take time to read the food labels to see if it contained GM ingredients while $46.6 \%$ said they never read food labels (Figure 8).

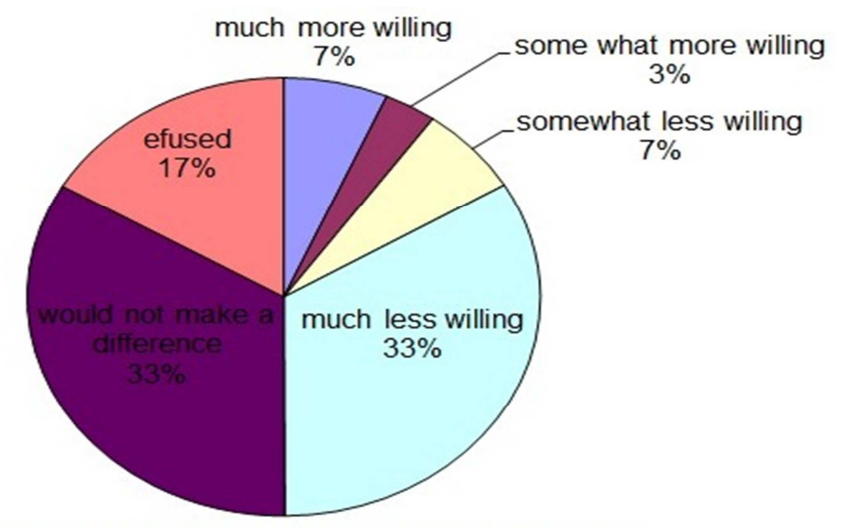

Figure 8: Effect of GM ingredient lable on willings to purchase food products

These results reveal the fact that people want the right to choose for themselves; they want genetically modified food labeled.

\section{Kind of Additional Information on Food Labels}

When asked about additional information they would be interested to see on food labels, half of the respondents mentioned genetic modification, $46.6 \%$ country of origin, $40 \%$ fat content and $40 \%$ irradiation, and $26.6 \%$ containing pesticides as shown in Table 4. 
Table 4: Additional Information on Food Labels

\begin{tabular}{|l|l|}
\hline & $\%$ \\
\hline Containing pesticide & 26.6 \\
\hline Containing GMOS & 50 \\
\hline Fat content & 40 \\
\hline Health benefits & 20 \\
\hline Grown locally & 20 \\
\hline Country of origin & 46.6 \\
\hline Certified organic & 50 \\
\hline Irradiated & 40 \\
\hline More information & 46.6 \\
\hline Other & 3.3 \\
\hline
\end{tabular}

Differences in Approval by Demographic Groups:

Age and education were found to be related to approval of GM food. Egyptians over 65 years reported less approval for GM food compared to those in other age groups. Among those aged over, $48 \%$ said they disapproved plant based GM foods; $20 \%$ do not know and 32\% approved while 56\% disapproved animal based GM food and $16 \%$ do not know; only $28 \%$ approved.

Respondents with graduate degrees were most likely to disapprove both plant based
(65\%) and animal based (76\%) GM foods. Only $22 \%$ and $20 \%$ approve plant and animal based GM foods respectively. On the other hand, respondents with primary and secondary school education were most likely to approve plant and animal based GM foods (58\% and 52\% respectively).

However, there was no relationship between gender and opinions of GM foods. Both men and women were more likely to disapprove plant based GM foods (55\% and $60 \%$ respectively) and animal based GM foods $(50 \%$ and $62.5 \%$ respectively) as shown in Tables 5, 6, and 7.

Table 5: Approval of GMF by Age

\begin{tabular}{|l|l|l|l|l|l|l|}
\hline & \multicolumn{4}{|l|}{ Plant based GM food } & \multicolumn{3}{l|}{ Animal based GM food } & \multicolumn{1}{l|}{$\begin{array}{l}\text { Don't } \\
\text { know }\end{array}$} \\
\hline Age & Approve & Disapprove & $\begin{array}{l}\text { Don't } \\
\text { know }\end{array}$ & Approve & Disapprove & 12 \\
\hline $18-24$ & 32 & 23 & 45 & 28 & 60 & 15 \\
\hline $25-34$ & 45 & 33 & 22 & 30 & 55 & 16 \\
\hline $35-44$ & 42 & 45 & 13 & 31 & 53 & 6 \\
\hline $45-54$ & 40 & 43 & 17 & 29 & 65 & 11 \\
\hline $55-64$ & 38 & 46 & 16 & 30 & 59 & 16 \\
\hline $\begin{array}{l}65 \\
\text { more }\end{array}$ & 32 & 48 & 20 & 28 & 56 & \\
\hline
\end{tabular}

Table 6: Approval of GM Foods by Education

\begin{tabular}{|l|l|l|l|l|l|l|}
\hline & \multicolumn{3}{|l|}{ Plant based GM food } & \multicolumn{3}{l|}{ Animal based GM food } \\
\hline Education & Approve & Disapprove & Don't know & Approve & Disapprove & Don't know \\
\hline Primary school & 58 & 12 & 30 & 52 & 14 & 34 \\
\hline Secondary school & 43 & 30 & 27 & 33 & 47 & 20 \\
\hline College & 39 & 46 & 15 & 35 & 55 & 10 \\
\hline $\begin{array}{l}\text { Post } \\
\text { Graduate }\end{array}$ & 22 & 65 & 13 & 20 & 67 & 13 \\
\hline
\end{tabular}


Table 7: Approval of GM Foods by Sex

\begin{tabular}{|l|l|l|l|l|l|l|}
\hline & \multicolumn{4}{|l|}{ Plant based GM food } & \multicolumn{3}{l|}{ Animal based GM food } \\
\hline Sex & Approve & Disapprove & Don't know & Approve & Disapprove & $\begin{array}{l}\text { Don't } \\
\text { know }\end{array}$ \\
\hline Male & 41.6 & 55 & 13.4 & 33.3 & 50 & 16.7 \\
\hline Female & 30 & 60 & 10 & 25 & 62.5 & 12.5 \\
\hline
\end{tabular}

\section{Organic Food Consumers and Approval of GM Foods:}

One fifth of respondents reported that they purchase organic food products and that they were less accepting of GM Food. Organic food purchasers had an approval rate of $23 \%$ and $27 \%$ respectively of plant and animal based GM foods compared with $52 \%$ and $32 \%$ of non-organic food purchasers. Sixty five percent of organic food purchasers reported that GM technology would make their quality of life worse compared to only $22 \%$ of nonorganic food purchasers. Organic food purchasers also reported that they know more about genetic modification (45\%) compared to (23\%) of non-organic purchasers.

\section{Food Allergies and Acceptance of GM Foods:}

There was no relationship between food allergy and approval of GM foods as allergic respondents, who made up one-fifth of the sample, were not less accepting of GM foods than the rest of respondents as 59\% of the food allergic respondents approved GM foods compared to only $41 \%$ of nonallergic respondents.

\section{Conclusion}

The present study is the first of its kind to be conducted in Egypt on genetically modified foods. The results of the present study revealed that the majority of respondents are unaware of the presence of GM foods in grocery stores in Egypt. Only a few respondents knew about genetically modified foods. Most respondents did not believe that genetically modified foods are sold in Egypt. Food safety, health, nutritional value and taste were the major issues affecting the purchase of GM foods while price and religious played a minor role in the purchase and consumption of GM foods. Most respondents consumed food without knowing that they were genetically modified. This may be due to lack of proper labeling.

\section{Acknowledgment}

I wish to thank Dr. W. K. Hallman of the State University of New Jersey for granting me permission to use his questionnaire in the present study.

\section{References}

Batalion, N. (2000). 50 Harmful Effects of Genetically Modified Foods, Americans for Safe Food, Oneonta New York, USA.

Central Agency for Public Mobilization and Statistics (2013).

El-Nawawi, F. (2012). 'Genetically Modified Organisms (Gmos) and Food Safety,' Egyptian Journal of Food Safety, 1(1) 1- 14.

Hallman, W. K., Hebden, W. C., Aquino, H. L., Cuite, C. L. \& Lang, J. T. (2003). Public Perceptions of Genetically Modified Foods: A National Study of American Knowledge and Opinion. (Publication Number RR1003-004). New Brunswick, New Jersey; Food Policy Institute, Cook College, Rutgers The State University of New Jersey.

Pattron, D. D. (2000) Fundamentals of Scientific Research, Scientific Publishers, New York.

Pattron, D. D. (2006). "A Survey of Genetically Modified Foods Consumed: Health Implications and Recommendations for Public Health Food Safety in Trinidad," Internet Journal of Food Safety, V (7): 4-14. 
Swinscow, T. D. V. (1991). 'Statistics at Square One,' London: British Medical Journal.

The Egyptian Legislation No. 242 (1997). Disapproving the Import of Foodstuffs Produced by the Use of Genetical Engineering Methods, Until Their Safety is Established.

http://www.egyptlaws.com/comprehensiv e06.html

The Egyptian Ministry of Trade and Industry (2012). The Evolution of Imports of the Arab Republic of Egypt from 2008 To 2012 http://www.mfti.gov.eg/index.asp

Verma, C., Nanda, S., Singh, R. K., Singh, R. B. \& Mishra, S. (2011). "A Review on Impacts of Genetically Modified Food on Human Health," The Open Nutraceuticals Journal, 4(1), Pp.3-11. 